\title{
Temel Eğitim Kurumlarında Görev Yapan Öğretmenlerin Okul Kültürü Algıları ile İş Doyumları Arasındaki İlişkinin İncelenmesi*
}

\author{
Investigation of the Relationship Between School Culture Perceptions and Job Satisfaction of Teachers at \\ Basic Education Level
}

Fatma Merve ÇELTEK (D), Elif YILMAZ* ${ }^{*}$ iD

\begin{abstract}
ÖZ
Amaç: Örgütsel yaşamda iş doyumu ve örgüt kültürü örgütlerin verimliliği ve çalışanların performansları açısından önemlidir. Bu durum eğitim örgütleri için de geçerlidir. Eğitim sistemi içerisinde önemli yerleri olan öğretmenlerin işlerinden doyum sağlamaları ve olumlu okul kültürüne sahip olmaları eğitimin kalitesi ve verimliliği için gerekli bir unsurdur. Öğretmenlerin mesleklerini başarılı bir şekilde yerine getirmesi mesleklerinin getirdiği sorumluluklardan hoşlanmaları, çalışıkları okula ait hissetmeleri, işlerinde kendilerini mutlu hissetmeleriyle bağlantılıdır. İşinden doyum sağlayan öğretmenlerin psikolojisi de yükselecektir. Literatür incelendiğinde güçlü okul kültürüne sahip okulların öğretmenlerin motivasyonunu artırarak işlerinden duydukları doyum düzeyini artırdığı görülmüştür. Bu bağlamda bu araştırmanın amacı temel eğitim kademesindeki öğretmenlerin okul kültürü algıları ile iş doyumları arasındaki ilişkinin incelenmesidir. Bu amaçla birlikte temel eğitim kademesindeki öğretmenlerin okul kültürü algıları ile iş doyum düzeylerinin cinsiyet, yaş, branş, mesleki kıdem yılı ve istihdam türü değişkenlerine göre anlamlı bir farklılık gösterip göstermediği incelenmiștir.

Yöntem ve Araçlar: Araştırma ilişkisel tarama modelinde tasarlanmıştır. Çalışma grubu Konya ili, Meram İlçesinde görev yapan 44 okul öncesi, 94 sınıf, 209 branş öğretmeni olmak üzere 347 öğretmenden oluşmaktadır. Araştırmada veri toplama araçları olarak, Kişisel Bilgi Formu, Okul Kültürü Ölçeği ve İ̧s Doyumu Ölçeği kullanılmıştır.

Sonuçlar: Araştırma sonuçlarına göre öğretmenlerin okul kültürü algıları ve alt boyutları ile iş doyumları arasında istatiksel olarak anlamlı bir ilişki tespit edilmiştir. Öğretmenlerin okul kültürü algıları demografik bilgilerine göre incelendiğinde cinsiyet değişkenine ilişkin anlamlı bir farklılık görülmezken yaş, branş, mesleki kıdem yılı, istihdam türüne ilişkin anlamlı farklılık görülmektedir. Öğretmenlerin iş doyum düzeyleri demografik değişkenlere göre incelendiğinde ise cinsiyet değişkeninde farklılaşma görülmektedir.

Anahtar Kelimeler: Temel eğitim, öğretmen, okul kültürü algısı, iş doyum düzeyi.

\section{ABSTRACT}

Purpose: In organizational life, job satisfaction and organizational culture are important in terms of the efficiency of organizations and the performance of employees. This is also true for educational organizations. It is a necessary element for the quality and efficiency of education that teachers, who have an important place in the education system, are satisfied with their jobs and have a positive school culture. Successful fulfillment of their profession by teachers is related to the fact that they enjoy the responsibilities of their profession, feel belonging to the school they work in, and feel happy in their work. Psychological well-being of teachers who are satisfied with their job will also be improved. It is seen in the related literature that schools with a strong school culture promote the motivation of teachers and increase the level of satisfaction they feel from their jobs. In this context, the aim of the present study was to examine the relationship between the perceptions of school culture and job satisfaction of teachers at the basic education level. For this purpose, the study investigated whether the perceptions of school culture and job satisfaction levels of teachers at the basic education level vary significantly by the variables of gender, age, branch, professional seniority and employment type.

Method and Materials: The research was designed in compatible with the causal-comparative model. The study group consists of 347 teachers, 44 of whom are pre-school, 94 classrooms, and 209 branches, working in the Meram District of Konya. Personal Information Form, School Culture Scale and Job Satisfaction Scale were used as data collection tools in the research.

Results: According to the results of the research, a statistically significant relationship was found between teachers' perceptions and sub-dimensions of school culture and their job satisfaction. When teachers' perceptions of school culture were analyzed according to their demographic information, there was no significant difference in terms of gender, while a significant difference was observed in age, branch, professional seniority, and employment type. When the job satisfaction levels of the teachers were analyzed according to the demographic variables, there was a difference in the gender variable.

Keywords: Basic education, teacher, school culture perception, job satisfaction level.
\end{abstract}

Bu araştırma Dr. Öğr. Üyesi Elif YILMAZ’ın danışmanlığında yürütülen Fatma Merve ÇELTEK’in yüksek lisans tezinin bir bölümünden üretilmiştir. “Karamanoğlu Mehmetbey Üniversitesi Eğitim Fakültesi Temel Eğitim Bölümü

Sorumlu Yazar/Correspondence Author: Dr. Öğr. Üyesi Elif YILMAZ

E-posta/E-mail: elifyilmaz@kmu.edu.tr

Geliş Tarihi/Received: 28.08.2021

Kabul Tarihi/Accepted: 06.11.2021

Ç. Yayınlanma Tarihi/Online Published: 30.11 .2021 


\section{GİRIŞ}

Günümüzde bilimsel, toplumsal, teknolojik ve siyasi gelişmeler doğrultusunda bireylerden beklenilen nitelikler değişime uğramış; buna bağlı olarak eğitim kurumlarının değişimi de zorunlu hale gelmiştir. Araştırma ve geliştirme merkeze alınarak bilginin üretilmesi için bilime, insana ve teknolojiye yatırım sağlayan eğitim ön plana çıkmıştır (Aktan ve Tunç, 1998). Bu bağlamda bilgi üretimi ve nitelikli insan gücü önemli bir yere sahiptir; okul öncesi eğitiminden başlayarak yükseköğretime kadar bireyin eğitim hayatının önemi her geçen gün artmaktadır. Çünkü eğitim kurumlarının öğrencilerin var olan yeteneklerini ortaya çıkarma ve yeni beceriler kazandırarak çağın getirdiği yeniliklere uyum sağlayan bireyler yetiştirme görevi bulunmaktadır (Şişman 2002). Özellikle de temel eğitim süreci bu konuda büyük bir yere sahiptir (Şişman, 2005).

Eğitimin verimliliği ve niteliği büyük oranda öğretmenlerin niteliği ile ilişkilendirilmektedir (Şişman, 2005). Öğretmenlerin alan bilgilerinin yeterli düzeyde olmasının yanında psikolojik açıdan sağlıklı olmaları da gerekmektedir. Öğretmenlerin psikolojik sağlıklarını etkileyen unsurlardan biri iş doyumudur çünkü bir toplumun daha mutlu, sağlıklı ve yaratıcı olması çalışanların iş doyum düzeyi ile yakından ilişkilidir (Aşık, 2010). Eren (2004) çalışanların işlerinden memnun oldukları oranda çalıştıklarını belirtirken, Alıç (1996) yorgun, kırgın, mutsuz çalışanların işlerinde verimli olamayacaklarını belirtmiştir. İş doyumu bireyin iş yeriyle ilgili beklentilerinden ve işiyle ilgili tutumlarından oluşmaktadır (Miner, 1992). İş doyumu ile ilgili araştırmalar ilk olarak 1920'li yıllarda başlamış ve 1940'larda Hawthorne tarafından bu konuda yapılan araştırmalarla önemi benimsenmiştir. Öğretmenler için iş doyumu; öğretmenlerin iş ortamına ve öğrencilerine karşı duygusal algıları veya öğretmenlerin mesleğinden memnun olma düzeyleri şeklinde tanımlanabilir (Vural, 2004).

Alan yazın incelendiğinde iş doyumu ve iş doyumunu etkileyen unsurlar üzerine çeşitli araştırmalara rastlanmıştır. Ingersoll’un (2001) yaptığı araştırmada öğretmenlerin iş doyum düzeyleri artıkça okulda kalma isteklerinin arttı̆̆ı; iş doyumları düşük olunca emeklilik isteme ve okuldan ayrılma davranışlarında bulundukları saptanmıştır. Özyürek (2009) tarafından yapılan araştırmada iş doyum düzeyinin yüksek olması çalışanların mutlu olmasını sağlarken, işten doyum sağlayamama durumunun ise çalışanların yabancılaşmasına ve uyum problemleri yaşamalarına, psikolojik sağlıklarının bozulmasına yol açtığı belirtilmiştir. Bunun yanında öğretmenlerin iş doyum düzeylerinin düşük olması yaşam doyumlarını da olumsuz yönde etkilemektedir (Vural, 2004). Demirtaş (2010) tarafından yapılan bir araştırmada öğretmenlerin örgütsel bağlılıkları ile iş doyumları arasında pozitif yönde anlamlı bir ilişki bulunmuştur. Bu sonuç ile öğretmenlerin çalıştığı kuruma bağlılıkları artıkça iş doyumlarının da arttığı, iş doyumları artıkça da örgütsel bağlılığın güçlendiği söylenebilir. Rhoades, Eisenberger ve Armeli (2001) tarafından yapılan çalışmada, algılanan örgütsel desteğin iş doyumunu olumlu etkilediği belirlenmiştir. Bu sonuca paralel olarak öğretmenlerin okullarından algıladıkları destek doğrultusunda işlerinden ve yöneticilerinden memnun olacakları söylenebilir.

İş doyumunu etkileyen önemli faktörlerden biri de örgütsel kültürdür. MacMillan (1999) tarafından yürütülen araştırmada öğretmenlerin iş doyumları üzerinde okul kültürünün pozitif yönde etkisi olduğu ve güçlü okul kültürüne sahip okullarda çalışan öğretmenlerin başarılı olduğu ve işlerinden daha fazla doyum sağladığı tespit edilmiştir. Önal ve Ekici (2012), okul kültürünü ortak hareket etmeyi ve bütünleşmeyi sağlayan, okul niteliğini belirlemeye yardımc1 olan idealler, değerler, normlar, inançlar, gelenekler ve diğer kültürel sembollerin tümü şeklinde tanımlamışlardır. Okul kültürü öğrencinin yaşantısını etkiler ve öğrencinin kişiliğinin şekillenmesinde önemli bir unsurdur; aynı zamanda okulun kişiliğini oluşturur ve diğer okullardan farklılıklarını yansıtır. Okul kültürü, ortak amaçlara yönelme konusunda kılavuzluk görevi yapar ve başarı için hangi adımların atılması gerektiğine yönelik gerekli olan normları oluşturur. Bu bağlamda güçlü okul kültürünün oluşturulması, okul başarısının sağlanması ve sürdürülebilmesi açısından temel gerekliliktir (Sergiovanni, 2001).

Okul kültürünün öğretmenler tarafından olumsuz olarak algılanması iş doyumunun düşmesine neden olmaktadır. Öğretmenlerin işlerinden doyum sağlayamamaları da mesleki yaşamlarında hayal kırıklı̆̆ı ve özsaygılarıyla ilgili problem yaşamalarına yol açmaktadır (Hargreaves, 1994). Bu durum, öğretmenlerin mesleki tükenmişlik yaşamlarına da neden olabilmektedir. Bu konudaki araştırmalar incelendiğinde öğretmenlerde tükenmişlik düzeyi ile iş doyumu arasında olumsuz bir ilişki olduğu görülmüştür (Yılmaz ve Aslan, 2018). Bunun yanında sosyal desteğin stres, bitkinlik, depresyon, düşük benlik algısı, isteksizlik gibi tükenmişlik düzeyine etki eden değişkenlerle olumsuz, iş doyumu düzeyi ile olumlu ilişkisi olduğu görülmüştür (Çivilidağ, 2011). Başka bir deyişle, sosyal destek arttıkça öğretmenlerin iş doyumu düzeyi artmakta, tükenmişlik azalmaktadır. Bu sonuçlar, okullarda verimliliğin, öğretmenlerin iş doyumlarının, motivasyonlarının ve bağlılıklarının artırılması için öğretmenlerin olumlu ve güçlü okul kültürü algılarına sahip olmalarının önemini göstermektedir. Güçlü örgütsel unsurların baskın olduğu örgütlerde, 
örgüt üyeleri arasındaki dayanışma ve iş birliği ruhunun yüksek ölçüde olduğu, çalışanların iş doyumlarında, örgütsel bağl1lık ve verimlerinde artış olduğu görülmüştür (Erdem ve İşbaşı, 2001).

Alan yazın incelendiğinde öğretmenlerin okul kültürü algıları ile iş doyumları arasında pozitif ilişki tespit edilen araştırmalara rastlanmıştır (Gligorović, Nikolić, Terek, Glušac ve Tasić, 2016; İşcan ve Timüroğlu, 2007; You, Kim ve Lim 2017). Kadığlu ve Güneş (2018), okul kültürünün iş doyumuna etkisini inceledikleri araştırmalarında öğretmenlerin okul kültürü algılarıyla iş doyum düzeyleri arasında yüksek düzeyli, pozitif yönde anlamlı bir ilişkinin olduğunu saptamışlardır. Bu bilgiler ışığında bu araştırmanın amacı, temel eğitim kademesinde görev yapan öğretmenlerin okul kültürü algıları ile iş doyumları arasındaki ilişkinin incelenmesidir. Bu genel amacın yanı sıra temel eğitim kademesindeki öğretmenlerin okul kültürü algıları ile iş doyumu düzeyleri cinsiyet, yaş, branş, mesleki kıdem, istihdam türü değişkenleri açısından da ele alınmıştır.

$\mathrm{Bu}$ amaçlar doğrultusunda şu sorulara yanıt aranmıştır:

1. Temel eğitim kademesindeki öğretmenlerin okul kültürüne yönelik algıları ne düzeydedir?

2. Temel eğitim kademesindeki öğretmenlerin iş doyumları ne düzeydedir?

3. Temel eğitim kademesindeki öğretmenlerin okul kültürü algıları ile iş doyumları arasında anlamlı bir ilişki var midır?

4. Temel eğitim kademesindeki öğretmenlerin okul kültürüne yönelik algıları ile cinsiyet, yaş, branş, mesleki kıdem yılı, istihdam türü değişkenleri arasında anlamlı fark var mıdır?

5. Temel eğitim kademesindeki öğretmenlerin iş doyumları ile cinsiyet, yaş, branş, mesleki kıdem yıll, istihdam türü değişkenleri arasında anlamlı fark var mıdır?

\section{YÖNTEM}

\section{Araştırma Deseni}

Temel eğitim kademesinde görev yapan öğretmenlerin okul kültürü algıları ile iş doyum düzeyleri arasındaki ilişkiyi tespit etmek üzere yapılan bu araştırmada genel tarama modellerinden betimsel nitelikte ilişkisel tarama modeli kullanılmıştır. Betimsel araştırmalar araştırılmak istenen durumu, bulguyu olduğu gibi belirleyen araştırmalardır. İncelenen durumu veya olayı ayrıntılarıyla araştırarak ne olduğunu tanımlamaya çalışmaktadır (Karakaya, 2009). İlişkisel tarama modelleri, genel tarama modellerinden biri olup iki ya da daha çok sayıda değişken arasındaki birlikte değişim varlığını veya derecesini belirlemeyi amaçlayan araştırma modelleridir (Büyüköztürk, Kılıç Çakmak, Akgün, Karadeniz ve Demirel, 2010). Bu kapsamda temel eğitim kademesinde görev yapan öğretmenlerin okul kültürü algıları ile iş doyum düzeyleri betimsel olarak incelenmiş ve ayrıca aralarındaki ilişki değerlendirilmiştir.

\section{Çalışma Grubu}

Araştırmanın evrenini 2020-2021 eğitim-öğretim yılında Konyảnın Meram ilçesinde temel eğitim kademesinde görev yapan okul öncesi, ilkokul ve ortaokul öğretmenleri oluşturmaktadır. İl Milli Eğitim Müdürlüğü ve TÜİK istatistik verilerine göre Meram ilçesinde 177 okul öncesi, 1427 ilkokul, 1717 ortaokul öğretmeni olmak üzere 3321 öğretmen görev yapmaktadır. Araştırmanın örneklemi ‘basit seçkisiz küme örnekleme’ yöntemi ile oluşturulmuştur. Seçkisiz küme örneklem, kümelerin tarafsız olarak seçildiği örnekleme yöntemidir (Christensen, Johnson ve Turner, 2015). Christensen, Johnson ve Turner (2015) evren büyüklüğü 3500 kişi için örneklem büyüklüğü \%95 güven aralığında 346 olarak hesaplamışlardır. Bu hesaplama baz alınarak 3321 evren büyüklüğü için 347 katılımcı seçilmiştir. Çalışma grubunu oluşturan öğretmenlerin cinsiyet, yaş, branş, kurum türü, mesleki kıdem yılı ve istihdam türüne ait frekans ve yüzde dağılımları Tablo 1' de gösterilmiştir. 
Tablo 1: Öğretmenlerin demografik özellikleri

\begin{tabular}{|c|c|c|c|}
\hline \multicolumn{2}{|c|}{ Demografik Özellikler } & $\mathbf{n}$ & $\%$ \\
\hline \multirow{2}{*}{ Cinsiyet } & Kadın & 208 & 59.9 \\
\hline & Erkek & 139 & 40.1 \\
\hline \multirow{4}{*}{ Yaş } & 30 ve altı & 75 & 21,6 \\
\hline & $31-40$ arası & 102 & 29.4 \\
\hline & $41-50$ aras 1 & 110 & 31.7 \\
\hline & 51 ve üzeri & 60 & 17.3 \\
\hline \multirow{3}{*}{ Branş } & Okul öncesi öğretmenliği & 44 & 12.7 \\
\hline & Sınıf öğretmenliği & 94 & 27.1 \\
\hline & Branş öğretmenliği & 209 & 60.2 \\
\hline \multirow{3}{*}{ Mesleki Kıdem } & $1-10 \mathrm{yll}$ & 110 & 31.7 \\
\hline & $11-20$ yll & 104 & 30 \\
\hline & 21 yıl ve üstü & 133 & 38.3 \\
\hline \multirow{3}{*}{ İstihdam Türü } & Kadrolu & 275 & 79.3 \\
\hline & Sözleşmeli & 42 & 12.1 \\
\hline & Ücretli & 30 & 8.6 \\
\hline
\end{tabular}

Tablo 1'de görüldüğ̈̈ üzere araştırmaya katılan öğretmenlerin 208'i $(\% 59,9)$ kadın, 139'u $(\% 40,1)$ erkektir. Öğretmenlerin 75’i (\%21,6) 30 ve altı yaș arasında, 102'si (\%29,4) 31-40 yaş arasında, 110’u (\%31,7) 41-50 yaș arasında, $60^{\prime} 1(\% 17,3) 51$ yaș ve üzerindedir. Örneklemi olușturan öğretmenlerin 44’ü (\%12,7) okul öncesi öğretmeni, 94'ü $(\% 27,1)$ sinıf öğretmeni, 209’u (\%60,2) branş öğretmenidir. 110’u (\%31,7) 1-10 yıl arası, 104’u (\%30) 11-20 yıl arası, 133’ u $(\% 38,3) 21$ y1l ve üstü mesleki kıdeme sahip olan öğretmenlerin 275’i $(\% 79,3)$ kadrolu 42'si $(\% 12,1)$ sözleșmeli, 30 ’u $(\% 8,6)$ ücretli olarak görev yapmaktadır.

\section{Veri Toplama Araçları}

Araştırmada veri toplama araçları olarak Kişisel Bilgi Formu, Okul Kültürü Ölçeği ve İş Doyumu Ölçeği kullanılmıştır.

Kişisel Bilgi Formu; araştırmaya katılan öğretmenlerin demografik özelliklerini (cinsiyet, yaş, branş, mesleki kıdem, istihdam türü) belirlemek üzere araştırmacı tarafından hazırlanmış 5 kapalı uçlu sorudan oluşmaktadır.

Terzi (2005) tarafından geliştirilen, 29 sorudan oluşan 5’li likert tipindeki 'Okul Kültürü Ölçeği’ bu araştırmada kullanılan ölçeklerden biridir. Ölçek; 'Görev Kültürü', 'Başarı Kültürü', 'Destek Kültürü’ ve 'Bürokratik Kültür' olmak üzere dört alt boyuta sahiptir. Destek kültürünün temelinde insan ilişkileri ve güven vardır. Örgütteki bireylerin arasında etkileşim ve bağlılık ön plandadır. Bașarı kültürleri başarıyla işini yapan üyeleri destekleyen örgütleri tanımlar. Bürokratik kültürlerde rasyonel ve yasal yapı ağır basar. Kişisel ilişkilerin önemli olmadığı bu kurumlarda yöneticilerin görevi kontrol ve denetimdir. Görev kültürünün ilgi odağında örgütsel amaçlar vardır. Bu kültüre sahip kurumlar iş merkezli örgütlerdir. Bu araştırmada Okul Kültürü Ölçeğỉnin Cronbach Alfa katsayıs1 .88 olarak hesaplanmıştır. Okul Kültürü Ölçeği’nin alt boyutlarının Cronbach Alfa katsayısı Destek Kültürü için .91, Başarı Kültürü için .85, Bürokratik Kültür için .84, Görev için .70 olarak bulunmuştur.

$\mathrm{Bu}$ çalışmada Tezer (1991) tarafından bireylerin işlerinden sağladıkları doyum düzeyini ölçmek amacıyla geliştirilmiş olan 10 soruluk 'İş Doyumu Ölçeği' de kullanılmıştır. Sorulara verilen cevaplar doyum-doyumsuzluk yönünden 1 ile 4 arası puanlanmaktadır. Ölçekte alınabilecek en düşük puan 10, en yüksek puan ise 40’tır. Yüksek puan bireyin işinden doyum sağladığının göstergesidir. Ölçeğin Cronbach Alfa katsayısı .87 olarak hesaplanmıştır.

\section{Verilerin Toplanması ve Analizi}

Veriler; 2020-2021 eğitim-öğretim yılında Konyảnın Meram ilçesindeki okul öncesi eğitim kurumları, ilkokullar ve ortaokullarda görev yapmakta olan öğretmenlerden pandemi nedeniyle Google Forms üzerinden hazırlanan ölçeklerle dijital ortamda toplanmıştır. Toplanan verilerin uygun bir şekilde doldurulup doldurulmadı̆̆ incelenmiştir. Toplanan verilerin analizi için istatistik paket programı kullanılmıştır.

Araştırmanın birinci alt problemi olan “Temel eğitim kademesindeki öğretmenlerin okul kültürüne yönelik algıları 
ne düzeydedir?” ve ikinci alt problemi olan “Temel eğitim kademesindeki öğretmenlerin iş doyumu düzeyleri nedir?” sorularını analiz etmek için standart sapma ve ortalama değerlerine bakılmıştır. Araştırmanın üçüncü ve en önemli alt problemi olan "Temel eğitim kademesindeki öğretmenlerin okul kültürü algıları ile iş doyumları arasında anlamlı bir ilişki var mıdır?” sorusuna yönelik analizler için ölçekler ve alt boyutları arasındaki ilişki derecesini ölçmek için Pearson korelasyon analizi uygulanmıştır. Araştırmanının dördüncü alt problemi olan "Temel eğitim kademesindeki öğretmenlerin okul kültürüne yönelik algıları cinsiyet, yaş, branş, kıdem yıll, istihdam türü değişkenlerine göre farklılaşmakta mıdır?” ve beşinci alt problemi olan “Temel eğitim kademesindeki öğretmenlerin iş doyumları cinsiyet, yaş, branş, kıdem yılı, istihdam türü değişkenlerine göre farklılaşmakta mıdır?” sorularını analiz etmek için öncelikle verilerin normal dağılıp dağılmadığına bakılmıştır. Yapılan Kolmogorov-Smirnov testi sonuçları ile çarpıklık ve basıklık kat sayıları incelenmiş ve verilerin normal dağılım gösterdiği belirlendikten sonra, iki gruptan oluşan değişkenler için bağımsız gruplar t-testi, ikiden fazla gruptan oluşan değişkenler için One Way-ANOVA (tek yönlü varyans analizi) uygulanmıştır. Tek yönlü varyans analizine göre gruplar arasında anlamlı farklılık olduğu durumlarda farklılı̆̆ın hangi gruplar arasında olduğunu belirlemek Tukey Testi yapılmıştır.

\section{BULGULAR}

Araştırmanın ilk sorusuna uygun olarak temel eğitim kademesindeki öğretmenlerin okul kültürlerine yönelik algılarını belirlemek için yapılan analiz sonuçları Tablo 2'de verilmiştir.

Tablo 2: Okul kültürü ölçeği ve alt boyutlarının istatistiksel değerleri

\begin{tabular}{ccccc}
$\begin{array}{c}\text { Okul Kültürü Ölçeği ve } \\
\text { Alt Boyutları }\end{array}$ & Min Ortalama & Max & Ortalama & Ss \\
\hline Destek Külttürü & & Ortalama & & .83 \\
Başarı Kültürü & 1.13 & 5.00 & 3.75 & .81 \\
Bürokratik Külttür & 1.00 & 5.00 & 3.83 & .76 \\
Görev Kültürü & 1.33 & 5.00 & 3.21 & .66 \\
\hline Okul Kültürü Ölçeği & 1.83 & 5.00 & 3.96 & .52 \\
\hline
\end{tabular}

Tablo 2 incelendiğinde Okul Kültürü Ölçeği ve alt boyutlarına ait ortalama ve sapma puanları; Destek Kültürü alt boyutundan aldıkları puanların aritmetik ortalaması 3.75, Başarı Kültürü alt boyutundan aldıkları puanların aritmetik ortalaması 3.83, Bürokratik Kültür alt boyutundan aldıkları puanların aritmetik ortalaması 3.21, Görev Kültürü alt boyutundan aldıkları puanların aritmetik ortalaması 3.96 ve Okul Kültürü Ölçeğinden alınan toplam puanların aritmetik ortalaması 3.64'tür. Alt boyutlar için ortalama puanlar karşılaştırıldığında en yüksek ortalama puanın Görev Kültürü alt boyutuna, en düşük ortalamanınsa Bürokratik Kültür boyutunda olduğu saptanmıştır. Bu bulgular doğrultusunda katılımcı öğretmenlerin görüşlerine göre okullarda var olan okul kültürü yapılarında Görev Kültürü boyutunun öne çıktığı görülmektedir. Bu alt boyutu sırasıyla Başarı Kültürü, Destek Kültürü, Bürokratik Kültür takip etmektedir.

Destek Kültürü alt boyutuna ait en düşük puan 1.13, Başarı Kültürü alt boyutuna ait en düşük puan 1, Bürokratik Kültür alt boyutuna ait en düşük puan 1.33, Görev Kültürü alt boyutuna ait en düşük puan 1.83’tür. Okul Kültürü Ölçeği toplam puanı ve alt boyutları için en yüksek puan 5’tir.

Araştırmanın ikinci sorusuna uygun olarak temel eğitim kademesindeki öğretmenlerin iş doyum düzeylerini belirlemek için yapılan analiz sonuçları Tablo 3’te verilmiştir.

Tablo 3: İş Doyumu Ölçeğinin İstatistiksel Değerleri

\begin{tabular}{lcccc}
\hline İş Doyumu Ölçeği & Min Ortalaması & Max Ortalaması & Ortalama & Ss \\
İș Doyumu & 1.40 & 4.00 & 3.24 & .51 \\
\hline
\end{tabular}

Öğretmenlerin İş Doyumu Ölçeğinden aldıkları puanların aritmetik ortalaması 3,24’tür. İş Doyumu Ölçeğinden alınan en düşük puan 1.40, en yüksek puan 4'tür.

Araştırmanın üçüncü sorusuna uygun olarak temel eğitim kademesindeki öğretmenlerin okul kültürü algıları ile 
iş doyumları arasındaki ilişkiyi saptamak için yapılan korelasyon analiz sonuçları Tablo 4’te verilmiştir.

Tablo 4: Okul Kültürü ve İş Doyumu Ölçeği Toplam Puanları için Pearson Korelasyon Analizi Sonuçları

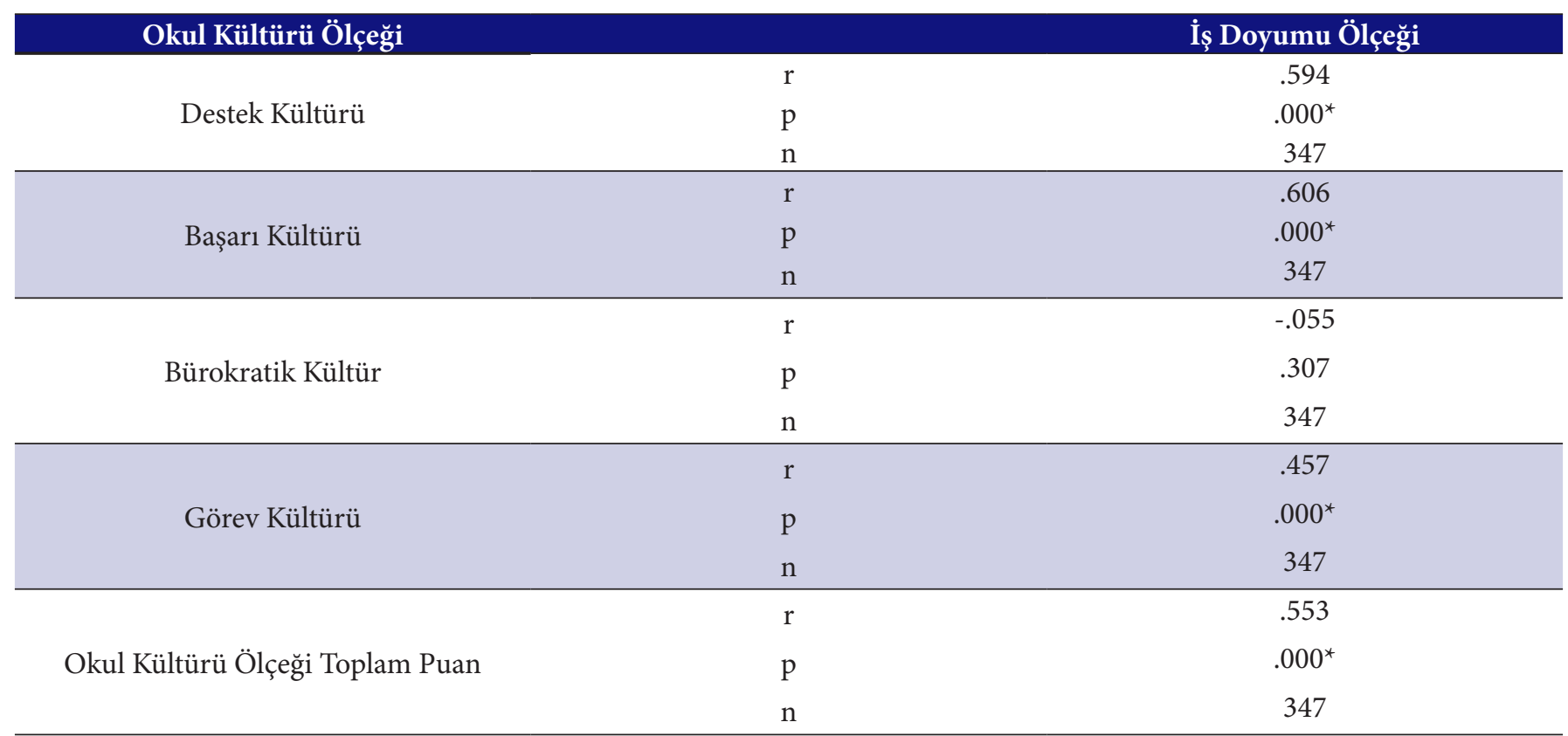

Araştırmada çalışmaya katılan öğretmenlerin Okul Kültürü Ölçeği’nin Destek Kültürü ( $r=.594)$, Başarı Kültürü ( $\mathrm{r}=.606)$, Görev Kültürü ( $\mathrm{r}=.457)$ alt boyutları ve Okul Kültürü Ölçeği toplam puan ortalamaları ( $\mathrm{r}=.553)$ ile İş Doyumu Ölçeği arasında pozitif yönde anlamlı bir ilişki olduğu bulunmuştur $(\mathrm{p}<.05)$. Buna ek olarak Okul Kültürü Ölçeği’nin Bürokratik Kültür alt boyutu ile İş Doyumu Ölçeği arasında istatistiksel olarak anlamlı bir ilişki saptanmamıştır ( $\mathrm{r}=-$ $.055 ; \mathrm{p}>.05)$.

Araştırmanın dördüncü sorusuna uygun olarak temel eğitim kademesindeki öğretmenlerin okul kültürü algılarının demografik değişkenlere yönelik anlamlı bir farklılık gösterip göstermediğini belirlemek için yapılan analiz sonuçları Tablo 5’te verilmiştir.

Tablo 5: Okul Kültürü Ölçeği Puan Ortalamalarının Yaş Grubu Değişkenine İlişkin ANOVA Sonuçları

\begin{tabular}{|c|c|c|c|c|c|c|c|c|c|c|c|}
\hline \multirow[b]{2}{*}{ Boyutlar } & \multicolumn{2}{|c|}{$\begin{array}{c}\text { A)30 yaş ve } \\
\text { altı } \\
n=75\end{array}$} & \multicolumn{2}{|c|}{$\begin{array}{c}\text { B) } 31-40 \text { yaş } \\
n=102\end{array}$} & \multicolumn{2}{|c|}{$\begin{array}{c}\text { C) } 41-50 \text { yaş } \\
n=110\end{array}$} & \multicolumn{2}{|c|}{$\begin{array}{c}\text { D)51 yaş ve } \\
\text { üzeri } \\
n=60\end{array}$} & \multirow[b]{2}{*}{$\mathbf{F}$} & \multirow[b]{2}{*}{$\mathbf{p}$} & \multirow[b]{2}{*}{$\begin{array}{l}\text { Fark } \\
\text { Yönü }\end{array}$} \\
\hline & $\bar{X}$ & Ss & $\bar{X}$ & Ss & $\bar{X}$ & Ss & $\bar{X}$ & Ss & & & \\
\hline Destek Kültürü & 3.82 & .72 & 3.80 & .84 & 3.76 & .91 & 3.56 & .78 & 1.32 & .265 & \\
\hline Başarı Kültürü & 3.87 & .70 & 3.85 & .81 & 3.87 & .90 & 3.65 & .74 & 1.11 & .343 & \\
\hline Bürokratik Kültür & 3.45 & .84 & 3.22 & .78 & 3.07 & .74 & 3.14 & .61 & 3.91 & $.009^{*}$ & $\mathrm{~A}-\mathrm{C}$ \\
\hline Görev Kültürü & 3.82 & .07 & 3.94 & .05 & 4.05 & .06 & 4.01 & .80 & 1.95 & .121 & \\
\hline Okul Kültürü Toplam & 3.72 & .53 & 3.64 & .46 & 3.63 & .57 & 3.54 & .49 & 1.28 & .281 & \\
\hline
\end{tabular}

Tablo 5 incelendiğinde öğretmenlerin okul kültürü alg1 düzeylerinde yaş değiş̧eninin Okul Kültürü Toplam puanlarında $(\mathrm{F}=1.28 ; \mathrm{p}=.281>.05)$, Destek Kültürü alt boyutunda $(\mathrm{F}=1.32 \mathrm{p}=.265>.05)$, Başarı Kültürü alt boyutunda $(\mathrm{F}=1.11 ; \mathrm{p}=.343>.05)$ ve Görev Kültürü alt boyutunda $(\mathrm{F}=1.95 ; \mathrm{p}=.121>.05)$ istatistiksel olarak anlamlı bir farkl1lık oluşturmadığı belirlenmiştir. Bürokratik Kültür alt boyutunda ise yaş değişkenine göre $(\mathrm{F}=3.91 ; \mathrm{p}=.009<.05)$ istatistiksel olarak anlamlı bir farklılık görülmektedir. Farklılığın 41-50 yaş arası öğretmenlerle 30 yaş ve altında olan öğretmenler arasında olduğu görülmektedir. Bu sonuç 30 ve altı yaş arası öğretmenlerin $(\overline{\mathrm{X}}=3.45) 41$ ve 50 yaş arası öğretmenlere $(\overline{\mathrm{X}}=3.07)$ göre bürokratik kültürün daha fazla olduğu okul kültürü algıladıkları yönünde değerlendirilebilir. 
Tablo 6: Okul Kültürü Ölçeği Puan Ortalamalarının Branş Değişkenine İlişkin ANOVA Sonuçları

\begin{tabular}{lcccccccccc} 
& \multicolumn{2}{c}{ A) Okul Öncesi } & \multicolumn{2}{c}{ B) Sinıf } & \multicolumn{2}{c}{ C)Branş } & & & \\
Boyutlar & $\overline{\mathbf{X}}$ & Ss & $\overline{\mathbf{X}}$ & Ss & $\overline{\mathbf{X}}$ & Ss & F & p & Fark \\
Yönü
\end{tabular}

Tablo 6 incelendiğinde öğretmenlerinin okul kültürü algı düzeylerinde branş değişkeninin Okul Kültürü Toplam puanlarında ( $\mathrm{F}=.757 ; \mathrm{p}=.470>.05)$, Destek Kültürü alt boyutunda ( $\mathrm{F}=.391 ; \mathrm{p}=.667>.05)$, Başarı Kültürü alt boyutunda $(\mathrm{F}=.226 ; \mathrm{p}=.798>.05)$ ve Görev Kültürü alt boyutunda $(\mathrm{F}=.792 ; \mathrm{p}=.454>.05)$ istatistiksel olarak anlamlı bir farklıllk oluşturmadığ belirlenmiştir. Bürokratik Kültür alt boyutunda ise branş değişkenine göre $(\mathrm{F}=3.66 ; \mathrm{p}=.027<.05)$ istatistiksel olarak anlamlı bir farklılık görülmektedir. Farklılığın okul öncesi öğretmenleri ile branş öğretmenleri arasında olduğu ve söz konusu farkın okulöncesi öğretmenleri lehine olduğu görülmektedir. Bu bulgular doğrultusunda okul öncesi öğretmenlerinin branş öğretmenlerine göre bürokratik kültürün daha fazla hissedildiği okul kültürü algıladıkları yönünde açıklanabilir.

Tablo 7: Okul Kültürü Ölçeği Puan Ortalamalarının Mesleki Kıdem Değişkenine İlişkin ANOVA Sonuçları

\begin{tabular}{|c|c|c|c|c|c|c|c|c|c|}
\hline \multirow[b]{2}{*}{ Boyutlar } & \multicolumn{2}{|c|}{ A)1-10 y1l } & \multicolumn{2}{|c|}{ B)11-20 y1l } & \multicolumn{3}{|c|}{ C)21 yıl ve üzeri } & \multirow[b]{2}{*}{$\mathbf{p}$} & \multirow[b]{2}{*}{$\begin{array}{l}\text { Fark } \\
\text { Yönï }\end{array}$} \\
\hline & $\overline{\mathbf{X}}$ & Ss & $\overline{\mathbf{X}}$ & Ss & $\overline{\mathbf{X}}$ & Ss & $\mathbf{F}$ & & \\
\hline Destek kültürü & 3.76 & .83 & 3.86 & .85 & 3.66 & .81 & 1.67 & .189 & \\
\hline Başarı Kültürü & 3.84 & .77 & 3.93 & .84 & 3.74 & .81 & 1.66 & .191 & \\
\hline Bürokratik Kültür & 3.43 & .83 & 3.08 & .72 & 3.12 & .70 & 7.16 & .001 & $\begin{array}{l}\text { A-B } \\
\text { A-C }\end{array}$ \\
\hline Görev Kültürü & 3.81 & .63 & 4.00 & .63 & 4.06 & .69 & 4.63 & .010 & C-A \\
\hline Okul Kültürü Toplam & 3.68 & .51 & 3.66 & .50 & 3.59 & .54 & 1.05 & ,348 & \\
\hline
\end{tabular}

Öğretmenlerin okul kültürü alg1 düzeylerinde mesleki kıdem değişkeninin Okul Kültürü Toplam puanında ( $\mathrm{F}=1.05 ; \mathrm{p}=.348>.05)$, Destek Kültürü alt boyutunda $(\mathrm{F}=1.67 ; \mathrm{p}=.189>.05)$, Başar1 Kültürü alt boyutunda $(\mathrm{F}=1.66$; $\mathrm{p}=.191>.05)$ istatistiksel olarak anlamlı bir farklılık oluşturmadığı belirlenmiştir.

Bürokratik Kültür ve Görev Kültürü alt boyutlarında ise mesleki kıdem değişkenine göre anlamlı farklılık görülmüştür. Bürokratik Kültür alt boyutunda mesleki kıdem değişkenine göre $(F=7.16 ; p=.001<.05)$ istatistiksel olarak anlamlı bir farklılık görülmektedir. Görev Kültürü alt boyutunda ise mesleki kıdem türü değişkenine göre $(\mathrm{F}=4.63 ; \mathrm{p}=.010<.05)$ istatistiksel olarak anlamlı bir farklılık vardır. Bürokratik Kültür alt boyutunda 1 ve 10 yıl arası kıdeme sahip olan öğretmenler $(\overline{\mathrm{X}}=3.43)$ ile 11 ve 20 yıl arasında kıdeme sahip öğretmenler $(\overline{\mathrm{X}}=3.08)$ arasında ve 1 ve 10 yıl arası kıdeme sahip olan öğretmenler ile 21 yıl üzeri kıdemli öğretmenler $(\overline{\mathrm{X}}=3.12)$ arasında anlamlı farklılık olduğu ve farklılı̆̆ın 1 ve 10 yıl arası kıdeme sahip öğretmenler lehine olduğu görülmektedir. Buna göre 1 ve 10 yıl arası kıdeme sahip öğretmenlerin Bürokratik Kültür alt boyutunu okul kültüründe daha fazla algıladıkları söylenebilir. Görev Kültürü alt boyutunda ise farklılaşma 1 ve 10 yıl arası kıdeme sahip olan öğretmenlerle $(\overline{\mathrm{X}}=3.81) 21$ yıl üzeri kıdemli öğretmenler arasında $(\overline{\mathrm{X}}=4.06), 21$ yıl üzerin kıdeme sahip öğretmenler lehine olduğu görülmektedir. Bu bağlamda 21 yıl ve üzeri kıdemli öğretmenlerin, 1 ve 10 yıl arası öğretmenlere göre Görev Kültürü alt boyutunu okul kültürü içinde daha fazla algıladıkları şeklinde değerlendirilebilir. 
Tablo 8: Okul Kültürü Ölçeği Puan Ortalamalarının İstihdam Türü Değişkenine İlişkin ANOVA Sonuçları

\begin{tabular}{lccccccccc} 
& \multicolumn{2}{c}{ A)Kadrolu } & \multicolumn{2}{c}{ B)Sözleşmeli } & \multicolumn{2}{c}{ C) Ücretli } & & & Fark \\
\multicolumn{1}{c}{ Boyutlar } & $\overline{\mathbf{X}}$ & Ss & $\overline{\mathbf{X}}$ & Ss & $\overline{\mathbf{X}}$ & Ss & F & p & Yönü \\
\hline Destek kültürü & 3.75 & .84 & 3.87 & .77 & 3.55 & .82 & 1.24 & .290 & \\
\hline Başarı Kültürü & 3.84 & .83 & 3.83 & .69 & 3.73 & .77 & .243 & .785 & \\
\hline Bürokratik Kültür & 3.15 & .75 & 3.37 & .80 & 3.53 & .72 & 4.58 & .011 & C-A \\
\hline Görev Kültürü & 4.00 & .66 & 3.90 & .53 & 3.67 & .76 & 3.81 & .023 & A-C \\
\hline Okul Kültürü Toplam & 3.63 & .51 & 3.71 & .49 & 3.61 & .64 & .243 & .785 & \\
\hline
\end{tabular}

İstihdam türü değişkeninin Okul Kültürü Toplam puanında ( $\mathrm{F}=.491 ; \mathrm{p}=.612>.05)$, Destek Kültürü alt boyutunda $(\mathrm{F}=1.24 ; \mathrm{p}=.290>.05)$, Başarı Kültürü alt boyutunda $(\mathrm{F}=.243 ; \mathrm{p}=.785>.05)$ istatistiksel olarak anlamlı bir farklılık oluşturmadığı belirlenmiştir. Bürokratik Kültür ve Görev Kültürü alt boyutlarında istihdam türü değişkenine göre istatistiksel olarak anlamlı bir farklılık görülmüștür. İstihdam türü değişkenine göre Bürokratik Kültür alt boyutu $(\mathrm{F}=4.58 ; \mathrm{p}=.011<.05)$ ile Görev Kültürü alt boyutunda ise $(\mathrm{F}=3.81 ; \mathrm{p}=.023<.05)$ istatistiksel olarak anlamlı bir farkl1lı görülmektedir.

Bürokratik Kültür alt boyutunda farklılaşma kadrolu öğretmenler $(\overline{\mathrm{X}}=3.15)$ ve ücretli öğretmenler $(\overline{\mathrm{X}}=3.53)$ arasında ve ücretli öğretmenlerin lehine olduğu görülmektedir. Ücretli öğretmenlerin kadrolu öğretmenlere göre Bürokratik Kültür alt boyutunu okul kültürü içerisinde daha fazla hissettikleri şeklinde açıklanabilir. Görev Kültürü alt boyutunda ise kadrolu öğretmenlerin, ücretli öğretmenlere göre görev kültürünün daha baskın olduğu okul kültürü algıladıkları yönünde değerlendirilebilir.

Araştırmanın dördüncü sorusuna uygun olarak temel eğitim kademesindeki öğretmenlerin iş doyum düzeylerinin demografik değişkenlere yönelik anlamlı bir farklılık gösterip göstermediğini belirlemek için yapılan analiz sonuçları Tablo 9'da verilmiştir.

Tablo 9: İş Doyumu Ölçeği Puan Ortalamalarının Cinsiyet Değişkenine Göre t Testi Sonuçları

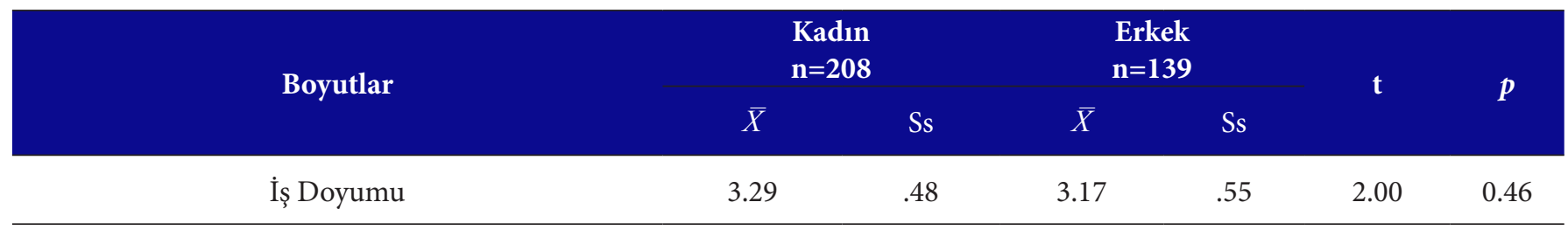

Tablo 9'da görüldüğü üzere öğretmenlerinin iş doyum düzeylerinin cinsiyet değişkeni $(t=2,00 ; p=0,46<0,05)$ ile istatistiksel olarak anlamlı bir farklılık oluşturduğu tespit edilmiştir. Kadın öğretmenlerin ortalamalarının 3.29 erkek öğretmenlerin ortalamalarına 3.17 olduğu ve kadın öğretmenlerin puan ortalamalarının erkek öğretmenlere göre daha yüksek olduğu görülmektedir. Bu bulgu doğrultusunda kadın öğretmenlerin erkek öğretmenlere göre iş doyum düzeylerinin daha yüksek olduğu söylenebilir.

\section{SONUÇ, TARTIŞMA VE ÖNERILLER}

$\mathrm{Bu}$ araştırma; temel eğitim kademesinde görev yapan öğretmenlerin okul kültürü algıları ile iş doyumları arasındaki ilişkinin incelenmesine, öğretmenlerin okul kültürü algıları ile iş doyumlarının çeşitli değişkenler açısından farklılaşıp farklılaşmadığının saptanmasına yönelik olarak yürütülmüştür.

Araştırmadan elde edilen ilk sonuca göre, örneklemi oluşturan 347 öğretmenin 'okul kültürü algılari' yüksek düzeydedir. Bununla birlikte öğretmenlerin görev yaptığı eğitim kurumlarında görev yönelimli bir kültürün baskın olduğu söylenebilir. Alan yazın incelendiğinde araştırma sonucuyla paralel bazı çalışmalara rastlanmıştır (Koşar, 2008; Terzi, 2005). Özdemir (2012) tarafından yapılan araştırmada öğretmenlerin görev yönelimli okul kültürü algıladıkları tespit edilmiştir. Yılmaz (2009) ise araştırmasında ilköğretim okullarında destek kültürü boyutunun daha baskın olduğu sonucuna ulaşmıştır. Okullarda görev kültürünün baskın olmasının muhtemelen okul yöneticilerinin beklenti ve tutumlarından kaynaklandığı düşünülebilir. Hassenboehler’e (2004) göre okul yöneticileri, öğretmenlerin görevlerini yapması yönünde büyük oranda yasal otorite kullanmaktadır. Decker (1989) ise bir araştırmasında yöneticilerin güç 
kullanımı ile öğretmenlerin algıladıkları okul ikliminin ilişkili olduğunu saptamıştır. Bu sonuçlardan yola çıkararak okul yöneticilerinin öğretmenleri etkiledikleri, okullarda görev kültürünün baskın olduğu ve öğretmenlerin görevlerini yerine getirmeyi ön planda tuttukları söylenebilir.

Araştırmanın bir diğer sonucuna göre öğretmenlerin 'iş doyumları' da yüksek düzeydedir. Bu sonuç alan yazındaki araştırmalar ile benzerlik göstermektedir (Cerit, 2009; Karakaya-Kadıoğlu ve Güneş, 2018). Şahin (2013) tarafından yapılan araştırmada ilköğretim öğretmenlerinin iş doyum düzeylerinin orta düzeyde olduğu saptanmıştır. Çetinkanat (2000) tarafından yapılan araştırmada iş doyumu ile meslektaş ilişkileri, çalışma olanakları, yönetim tarzları ve çalışma ortamı arasında yüksek düzeyde ilişki olduğu ifade edilmiştir. Temel eğitim kademesinde görev yapan öğretmenlerin iş doyum düzeylerinin yüksek olarak belirlenmesinde meslektaş ilişkileri, öğrencilerle daha fazla iletişim kurabilme imkânına sahip olma, çalışma saatleri, çalışma ortamı ve mesleki devamlılığın etkili olduğu düşünülebilir.

Araştırmada öğretmenlerin okul kültürü algıları ile iş doyum düzeyleri arasında pozitif yönde anlamlı bir ilişki bulunmuştur. Bu sonuca göre; okul kültürü puanları artıkça iş doyumu puanlarının da arttığı, okul kültürü algısı yüksek olan öğretmenlerin iş doyum düzeylerinin de yüksek olacağı öngörülmektedir. Güçlü okul kültürü ile okul, öğrenci ve öğretmen başarısı, öğretmenlerin motivasyonu ve iş doyumları arasında yüksek düzeyde ilişkiler bulunmaktadır (Stolp, 1994). Okul kültürünün öğretmenler tarafından olumlu algılanması, iş doyumunu artıran önemli bir unsurdur. Bu doğrultuda hem iş doyum düzeyini hem de okul başarısını artırıcı güçlü bir okul kültürünün inşa edilmesinin önemli olduğu söylenebilir. Araştırmanın bu sonucunu Çevik ve Köse (2017), Hosseinkhanzadeh, Hosseinkhanzadeh ve Yeganeh (2013), Karakaya-Kadığlu ve Güneş (2018), Özdemir (2006), Wong (2010), You, Kim ve Lim (2017) tarafından yapılan araştırmalar da desteklemektedir.

Temel eğitim kademesindeki okullarda görev yapan öğretmenlerin okul kültürü algıları 'yaş' değişkeni açısından incelendiğinde 30 yaş ve altı öğretmenlerle 41-50 yaş arası öğretmenler arasında Bürokratik Kültür alt boyutunda istatistiksel olarak anlamlı bir fark görülmüsşür, yani 30 yaş ve altı öğretmenlerin 41-50 yaş arası öğretmenlere göre bürokratik kültür boyutunu okullarda daha çok algıladıkları sonucuna ulaşılmıştır. Işıı (2017) tarafından yapılan araştırmada benzer sonuçlara rastlanmıştır. Bu durumun nedeni olarak genç öğretmenlerin daha fazla özgürlük ve esnek çalışma beklentilerine sahip olduğu düşünülebilir.

Öğretmenlerin okul kültürü algıları 'branş’ değişkenine göre incelendiğinde okul öncesi öğretmenlerinin branş öğretmenlerine göre okullarında daha fazla bürokratik kültürü algıladıkları tespit edilmiştir. Eğitim programının okul öncesi eğitimde esnek olması, öğretimde akademik başarı kaygısının bulunmaması gibi nedenler sınıf öğretmenleri ve branş öğretmenlerine göre okul öncesi öğretmenlerinin bürokratik kültür algılarını etkilediği düşünülebilir. Oğuz ve Yılmaz (2006) tarafından yapılan araştırmada öğretmenlerin okul kültürü algılarının branş değişkenine göre anlamlı bir fark oluşturmadığını görülmüştür.

Öğretmenlerin okul kültürü algıları 'mesleki kıdem' değişkenine göre incelendiğinde ise farklılık bürokratik kültür ve görev kültürü alt boyutlarında görülmüştür. Bürokratik kültür boyutunda 1-10 yıl arası kıdeme sahip öğretmenlerin 11-20 yıl arası ile 21 yıl ve üzeri kıdemli öğretmenlere göre bürokratik kültür alt boyutunu okul kültüründe daha fazla algıladıkları saptanmıştır. Görev kültürü boyutunda 21 yıl ve üzeri kıdemli öğretmenlerin görev kültürü alt boyutu ortalama puanlarının daha yüksek olduğu görülmektedir. Bu bağlamda 21 yıl ve üzeri kıdemli öğretmenlerin, 1-10 yıl arası öğretmenlere göre görev kültürü alt boyutunu okul kültürü içinde daha fazla algıladıkları şeklinde değerlendirilebilir. Benzer şekilde Terzi (2005) ve Öztürk (2015) tarafından yapılan araştırmalarda da 10 yıl ve üzeri kıdeme sahip öğretmenlerin okullarında görev kültürünü daha baskın algıladıkları sonucuna ulaşılmıştır. Meyer ve diğerleri (1993) tarafından yapılan araştırmada yaş ve mesleki kıdem artıkça örgüte olan bağlılığın da artmasına ve yaşın ilerlemesiyle alternatif iş imkânlarının azalmasına vurgu yapılmıştır. Bu durumda tecrübeli öğretmenlerin okullarına ve görevlerine daha çok bağlanacakları söylenebilir.

Temel eğitim kademesindeki öğretmenlerin okul kültürü algıları 'istihdam türü’ değişkenine göre incelendiğinde farklılığın bürokratik ve görev kültürü alt boyutlarında olduğu görülmüştür. Ücretli öğretmenler, kadrolu öğretmenlere göre okullarında bürokratik kültürü daha baskın algılamaktadır. Görev kültürü boyutunda ise kadrolu öğretmenlerin ücretli öğretmenlere göre görev kültürünü daha fazla algıladıkları saptanmıştır. Bu farklılaşmanın olası sebebi olarak ücretli öğretmenler ile kadrolu öğretmenlerin yönetimden farklı şekillerde etkilendiği söylenebilir. Yalçın, Özan ve Özdemir (2021) tarafından yapılan araştırmada ücretli öğretmenlerin yönetimden kaynaklı olarak ayrımcılık yapıldığı ve ikinci planda kaldıklarını hissettikleri belirtilmiştir. Kadığlu-Ateş ve Vatansever-Bayraktar’ın (2018) yürüttüğü araştırmada sınıf öğretmenlerinin okul kültürü algıları ile istihdam türü değişkeni arasında anlamlı fark olduğunu tespit etmişlerdir. 
Araştırmanın son bulgusuna göre, kadın öğretmenlerin erkek öğretmenlere göre iş doyum düzeylerinin daha yüksek olduğu tespit edilmiştir. Benzer sonuçlar Clark (1997) tarafından yapılan araştırmada da bulunmuştur. Bu sonucun nedeni olarak kadın öğretmenlerin meslektaşları ve öğrencileriyle etkileşiminin erkek öğretmenlere göre daha yüksek olduğu şeklinde açıklanabilir. Bu nedene paralel olarak Centres ve Bugental (1966) yapmış oldukları araştırmada, kadınlarda iş doyum düzeyinin erkeklere oranla daha yüksek olduğunu, bunun nedeni olarak da kadınların işle ilişkili sosyal faktörleri daha çok önemsediklerini ifade etmişlerdir.

Araştırma sonuçlarından yola çıkarak öğretmenlerin iş doyumlarını artırmak okullarda destek kültürünün gelişimini sağlayarak işbirlikçi çalışma, dayanışma, karşılıklı güven ve başarıya yönelik yüksek beklenti gibi değerlerin aktarılması sağlanmalıdır. Bu doğrultuda yönetici ve öğretmenler başta olmak üzere okul üyeleri daha fazla demokratik tutum ve davranışlarda bulunmaları yönünde eğitilmeli ve teşvik edilmelidir. Öğretmenlerin iş doyum düzeyleri öğretmenlerin alan bilgileriyle de orantılıdır. Öğretmenlik mesleği süresince öğretmenlerin gelişimine katkı sağlayacak hizmet içi eğitimlerin verilmesi sağlanabilir.

\section{KAYNAKÇA}

Aktan, C. C. ve Tunç, M. (1998). Bilgi toplumu ve Türkiye. Yeni Türkiye Dergisi, 4(19), 118-134.

Alıç, M. (1996). Eğitim sisteminin amaçlarının gerçekleştirilmesinde eğitim yöneticisinin işlevleri. Çağdaş Eğitim Dergisi, 217, 12-16.

Aşık, N. A. (2010). Çalışanların iş doyumunu etkileyen bireysel ve örgütsel faktörler ile sonuçlarına ilişkin kavramsal bir değerlendirme. Türk İdare Dergisi, 467(6), 31-51.

Büyüköztürk, Ş., Çakmak, E. K., Akgün, Ö. E., Karadeniz, Ş. ve Demirel, F. (2010). Bilimsel araştırma yöntemleri. Ankara: Pegem Akademi.

Centers, R., \& Bugental, D. E. (1966). Intrinsic and extrinsic job motivations among different segments of the working population. Journal of Applied Psychology, 50(3), 193-197.

Cerit, Y. (2009). The effects of servant leadership behaviors of school principals on teachers' job satisfaction. Educational Management Administration and Leadership, 37(5), 600-623.

Christensen, R., Burke J. ve Turner. L. (2015). Araştırma yöntemleri: Desen ve analiz, 2. Baskı. Ankara: Anı

Clark, A. E. (1997). Job satisfaction and gender: Why are women so happy at work. Labour Economics, 4(4), 341-372.

Çetinkanat, C. (2000). Örgütlerde güdüleme ve iş doyumu. Ankara: Anı

Çevik, A. ve Köse, A. (2017). Öğretmenlerin okul kültürü algıları ile motivasyonları arasındaki ilişkinin incelemesi. Journal of the Human \& Social Science Researches, 6(2), 996-1014.

Çivilidağ, A. (2011). Üniversitelerdeki öğretim elemanlarının psikolojik taciz (mobbing), iş doyumu ve algılanan sosyal destek düzeyleri. Selçuk Üniversitesi, Eğitim Bilimleri Enstitüsü, Konya.

Decker, S. R. (1989). The relationship among principal power tactic usage, leadership style and school climate in selected Iowa elementary schools. University of Northern Iowa, USA.

Demirtaş, H. (2010). Dershane öğretmenlerinde örgütsel bağlllık ve iş doyumu. İnönü Üniversitesi Eğitim Fakültesi Dergisi, 11(2), 177-206.

Erdem, F. ve İşbaşı, J. Ö. (2001). Eğitim kurumlarında örgüt kültürü ve öğrenci alt kültürünün algılamaları. Akdeniz İktisadi ve İdari Bilimler Fakültesi Dergisi, 1(1), 33-57.

Eren, E. (2004). Örgütsel davranışve yönetim psikolojisi. İstanbul: Beta

Gligorovic, B., Nikolic, M., Terek, E., Glusac, D., \& Tasic, I. (2016). The impact of school culture on Serbian primary teachers' job satisfaction. Hacettepe University Journal of Education, 31(2), 231-248.

Hargreaves, A. (1994). Changing teachers, changing times. London: Cassell

Hassenboehler, D. (2004). The exercise of power by high school principals, (Unpublished Doctoral Dissertation). University of New Orleans, USA.

Hosseinkhanzadeh, A. A., Hosseinkhanzadeh, A., \& Yeganeh, T. (2013). Investigate relationship between job satisfaction and organizational culture among teachers. Procedia-Social and Behavioral Sciences, 84, 832-836.

Ingersoll, R. M. (2001). Teacher turnover, teacher shortages, and the organization of schools. Seattle, WA: Center for the Study of Teaching and Policy. 
Işık, H. (2017). Ortaokullarda okul kültürünün incelenmesi. İstanbul Aydın Üniversitesi Dergisi, 9(3), 61-71.

İşcan, Ö. F. ve Timuroğlu, M. K. (2007). Örgüt kültürünün iş tatmini üzerindeki etkisi ve bir uygulama. Atatürk Üniversitesi İktisadi ve İdari Bilimler Dergisi, 21(1), 119-135.

Kadığlu-Ateş, H. ve Vatansever-Bayraktar, H. (2018). Sınıf öğretmenlerinin okul kültürü algısı ile iş doyumu arasındaki ilişki. Electronic Turkish Studies, 13(19), 127-162.

Karakaya-Kadığlu, S. ve Güneş, D. Z. (2018) Okul kültürünün öğretmenlerin iş doyumuna etkisi. İZÜ Eğitim Dergisi, 1(2), 320346.

Karakaya, İ. (2009). Bilimsel Araştırma Yöntemleri. Ankara: Anı

Koşar, S. (2008). İlköğretim okulu yöneticilerinin yönetimde gücü kullanma stilleri ile örgüt kültürü arasındaki ilişki. (Yayınlanmamış Yüksek Lisans Tezi). Gazi Üniversitesi Eğitim Bilimleri Enstitüsü, Ankara.

Macmillan, R. B. (1999). Influences of workplace conditions on teachers job satisfaction. The Journal of Educational Research, 93(1), 39-47.

Meyer, J. P., Allen, N. J., \& Smith, C. A. (1993). Commitment to organizations and occupations: Extension and test of a threecomponent conceptualization. Journal of applied psychology, 78(4), 538.

Miner, J. B. (1992). Industrial-organizational psychology. New York: McGraw-Hill Book Company.

Oğuz, E. ve Yılmaz, K. (2006). İlköğretim okulu öğretmenlerinin okul kültürüne ilişkin algıları (Yozgat Örneği). Eğitim ve Bilim, 31(142), 89-98.

Önal, H. İ. ve Ekici, S. (2012). Okul kütüphanecilerinin görüşlerine göre okul kültürü değerlendirmesi. Bilgi Dünyası, 13(1), 138164.

Özdemir, A. (2006). Okul kültürünün oluşturulması ve çevreye tanıtılmasında okul müdürlerinden beklenen ve onlarda gözlenen davranışlar. Türk Eğitim Bilimleri Dergisi, 4(4), 411-436.

Özdemir, S. (2012). İlköğretim okullarında okul kültürü ile örgütsel sağlık arasındaki ilişki. Kuram ve Uygulamada Eğitim Yönetimi, 4(4), 599-620.

Öztürk, U. C. (2015). Örgüt kültürü algısında cinsiyet faktörünün etkisi ve bir uygulama. Süleyman Demirel Üniversitesi Vizyoner Dergisi, 6(12), 62-86.

Özyürek, A. (2009). Okul öncesi eğitimi öğretmen ve yöneticilerinin iş doyumu, kişisel özellik ve mesleki yeterlik algılarının değerlendirilmesi, Milli Ĕ̆itim Dergisi, 182, 8-21

Rhoades, L., Eisenberger, R., \& Armeli, S. (2001). Affective commitment to the organization: the contribution of perceived organizational support. Journal of Applied Psychology, 86(5), 825-836.

Sergiovanni, T. (2001). The principals: A reflective practice perspective. Boston: Allyn And Bacon.

Stolp, S. (1994). Leadership for school culture. East Lansing, MI: National Center for Research on Teacher Learning.

Şahin, İ. (2013). Öğretmenlerin iş doyumu düzeyleri. Yüzüncü Yıl Üniversitesi Eğitim Fakültesi Dergisi, 10(1), 142-167.

Şişman, M. (2002). Örgütler ve kültürler. Ankara: Pegem Akademi.

Şişman, M. (2005). Öğretmenliğe giriş, 8. Baskı. Ankara: Pegem Akademi.

Terzi, A. R. (2005). İlköğretim okullarında örgüt kültürü. Kuram ve Uygulamada Eğitim Yönetimi, 43(43), 423-442.

Tezer, E. (1991). İş doyumu ölçeği. Hacettepe Üniversitesi Sosyal Hizmetler Yüksekokulu Dergisi, 9(1-2-3), 55-76.

Vural, B. A. (2004). Kurum kültürü. İstanbul: İletişim Yayınları.

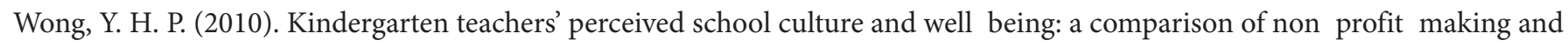
profit冈making kindergartens. Early Child Development and Care, 180(3), 271-278.

Yalçın, A. Y., Özan, M. B. ve Özdemir, T. Y. (2021). Ücretli öğretmenlerin örgütsel sosyalleşmesi üzerine bir çalışma. International Journal of Social Science Research, 10(1), 122-136.

Yılmaz, E. ve Aslan, S. (2018). Lise öğretmenlerinde tükenmişlik, iş doyumu ve algılanan sosyal destek: Bursa ili örneği. Abant İzzet Baysal Üniversitesi Eğitim Fakültesi Dergisi, 18(3), 1861-1886.

Yılmaz, F. (2009). Eğitim örgütlerinde örgüt kültürünün öğretmenlerin iş motivasyonu üzerindeki etkisi. Selçuk Üniversitesi Sosyal Bilimler Enstitüsü, Konya.

You, S., Kim, A. Y., \& Lim, S. A. (2017). Job satisfaction among secondary teachers in korea: effects of teachers' sense of efficacy and school culture. Educational Management Administration \& Leadership, 45(2), 284-297. 


\title{
Investigation of the Relationship Between School Culture Perceptions and Job Satisfaction of Teachers at Basic Education Level
}

\author{
Fatma Merve ÇELTEK (DD, Elif YILMAZ iD
}

\section{Introduction and purpose}

The aim of the present study was to determine the relationship between teachers' perceptions of school culture and their job satisfaction. In addition to this purpose, it was aimed to determine whether the teachers at the basic education level differ in terms of gender, age, branch, professional seniority, and employment type by determining their school culture perceptions and job satisfaction levels.

\section{Literature Review}

The efficiency and quality of education is largely proportional to the quality of teachers (Şişman, 2005). It is important for the quality of education that teachers are psychologically healthy as well as having a sufficient level of field knowledge. One of the factors affecting the psychological health of teachers is job satisfaction. One of the important factors affecting job satisfaction is organizational culture. The inability of teachers to be satisfied with their jobs leads to frustration and problems with their self-esteem in their professional lives (Hargreaves, 1994). When the literature was examined, studies were found that showed a positive relationship between teachers' perceptions of school culture and their job satisfaction (Gligorović, Nikolić, Terek, Glušac, \& Tasić, 2016; İșcan \& Timüroğlu, 2007; You, Kim \& Lim 2017).

\section{Methodology}

The study was conducted in relational survey model as a descriptive study. The sample of the study consisted of 347 teachers and data were collected from 347 teachers working in Meram, Konya. The study group of the study consists of 44 pre-school teachers, 94 classroom teachers, 209 branch teachers, 208 women and 139 men. The study employed the School Culture Scale developed by Terzi (2005) and consisting of 29 questions and the Job Satisfaction Scale consisting of 10 questions developed by Tezer (1991). The Cronbach Alpha coefficient of the School Culture Scale is .88. The Cronbach Alpha coefficient of the Job Satisfaction Scale is .87. A personal information form with questions about teachers' demographic information was added to the scales. The School Culture Scale consists of four dimensions: duty culture, support culture, success culture, and bureaucratic culture. Mean, standard deviation, percentage and frequencies were used in the analysis of the obtained data, independent t-test and ANOVA were performed in the analysis of differences; Correlation was used to analyze the relationship.

\section{Results, conclusion and suggestions}

According to the results of the research, a statistically significant relationship was found between teachers' perceptions and sub-dimensions of school culture and their job satisfaction. According to the results of the school culture analysis, duty culture is the sub-dimension of school culture that is intensely perceived in schools. When the perceptions of the school culture of the teachers at the basic education level were examined according to the demographic information of the teachers, there was no significant difference regarding the gender variable, but there was a significant difference regarding the age, branch and employment type. When the perceptions of school culture 
were examined according to the age variable, it was concluded that the teachers aged 30 and below perceived the bureaucratic culture dimension more in schools than the teachers aged 41-50. According to the branch variable, it was observed that preschool teachers perceived bureaucratic culture more in their schools than branch teachers. When the perceptions of school culture of the teachers at the basic education level were examined according to the variable of seniority, differentiation was observed in the sub-dimensions of duty and bureaucratic culture. The result is in favor of teachers with a seniority of 1-10 years. When examined by employment type, it was seen that paid teachers perceived the bureaucratic culture more dominantly in their schools than permanent teachers. In the dimension of task culture, it was determined that permanent teachers perceived task culture more than paid teachers. When the job satisfaction level was analyzed according to the demographic information of the teachers, there was a significant difference regarding the gender variable, while there was no significant difference regarding the age, branch, professional seniority and employment type. Job satisfaction levels of female teachers are higher than male teachers.

In order to increase the job satisfaction of teachers, it is recommended to reorganize and improve the physical conditions of the school, such as laboratories, technology classes, sports fields, according to the needs. In addition, it should be ensured that values such as collaborative work, solidarity, mutual trust and high expectation for success should be transferred by ensuring the development of a culture of support in schools. In this direction, school members, especially administrators and teachers, should be trained and encouraged to have more democratic attitudes and behaviors. Teachers' job satisfaction levels are also proportional to teachers' field knowledge. During the teaching profession, in-service trainings that will contribute to the development of teachers can be provided.

Bu makaleye atıf yapmak için / To cite this article:

Çeltek, F. M. \& Yılmaz, E. (2021). Temel eğitim kurumlarında görev yapan öğretmenlerin okul kültürü algıları ile iş doyumları arasındaki ilişkinin incelenmesi. Temel Eğitim Araștirmaları Dergisi, 1(2): 99-111. doi: 10.29228/tead.7 